\title{
Sexual Fashioning of Transgressive Selves among the Iranian Dutch Younger Generation
}

\author{
Rahil Roodsaz
}

\begin{abstract}
As a minority group with an Islamic background the Iranian Dutch are known as 'well-integrated' citizens, based on their educational and occupational position in society. By taking a liberal stance on homosexuality, premarital sex and nonmarital cohabitation, as currently contested topics in Dutch public debates on multiculturalism, a considerable number of them claims a 'modern' attitude. This paper considers a network of young Iranian Dutch who reject what they view as restrictive sexual norms imposed by the rest of the community and instead choose to fashion an ideal queer self. According to an Iranian Dutch dominant modernity discourse, romantic premarital sexual encounters, biologically-determined homosexuality and long-term committed non-marital cohabitation are acceptable. However, this young and highly educated group appropriates an alternative approach. Decoupling sex from romance, engaging in same-sex practices while rejecting homosexuality as an identity category and perceiving cohabitation as a potential form of sexual limitation, enables this group to negotiate with norms of intimacy. Analyzing the deployment of sexuality as practices of self-fashioning based on ethnographic data gathered between 2010 and 2013, this paper illustrates how cultural boundary-crossing in this context is at times accompanied by normative articulations of gender. It questions the predominantly celebrative interpretation of the at-the-cutting-edge configurations of the intimate life and argues for an analytical framework that seeks to unravel socio-cultural embeddedness of notions of transgression. Furthermore, it contributes to the range of studied transgressive practices of intimacy at the start of the $21^{\text {st }}$ century in which diasporic accounts are rather scarce.
\end{abstract}

Keywords: Self-fashioning, Iranian Dutch, transgression, sexual narratives.

\section{The respondents ${ }^{1}$}

The group of people I will talk about here is relatively homogenous. It includes only young men and women in their twenties and thirties. All of them are interested in different cultural, social and/or political issues, which is reflected in their choices of study or occupation. They are highly educated and have at least a Master's degree. Furthermore, all of them come from middle-class families who were politically active in Iran. Five of them live in Amsterdam. The other two live also in the Randstad, which is Dutch for the highly urbanized area of the western 
Netherlands, referring to the four cities of Amsterdam, Utrecht, Rotterdam and The Hague. Talking about issues of identity with these respondents, often meant an emphasis on the importance of the city for how they would position themselves - 'I am an Amsterdammer' - rather than Iranian, Dutch or an Iranian Dutch, while they ascribed a progressive, cosmopolitan mentality to people living in such urban contexts that they felt was lacking in the rest of the country and among Iranians in general. Moreover, they have an international group of friends, some of whom are expats from a variety of countries such as Spain, Italy, Portugal, Germany, the US and the UK. This meant that speaking English in everyday life is a common practice for them.

\section{Transgressive sexualities}

Both long-lasting and monogamous relationships were questioned by Sina, a young highly-educated Iranian man. With his parents and sisters, he had migrated to the Netherlands about 15 years before. Sina was finishing his MA in architecture at the time of our conversation in a café in Amsterdam. Based on his previous relationships and observations among friends, Sina was convinced that couples in a relationship should avoid living together. He said he would prefer living with a group of friends:

[S]o that I don't feel lonely. If I have a partner, of course, she can visit me and stay for a night or two. [...] I think we can even have children, without living together. That way we can have other relationships as well, if we want to.

When I asked him where he imagined their child would live he said:

That doesn't really matter. For instance, they could live with me and my friends. People think that children should necessarily live with their mother and father, but living with more people can also be educational and fun.

He also mentioned other possible household formations to make clear that such arrangements could always be made depending on the specific situation. However, he said, 'this is of course a hypothetical situation. No one probably wants to live like this except me with my fekraye ajib-gharibam [crazy thoughts].'

Idealizing open relationships, as a better alternative for monogamy, was mentioned by others as well. For instance, Mohsen, a man in his thirties cohabiting with his female partner, said:

Probably everyone feels the need to have sex with someone other than their partner from time to time. These feelings cannot be 
denied. I just don't see any good reason why people shouldn't allow themselves to act on those emotions.

Mohsen connected what he assumed a shared desire for having multiple sexual partners to mutual understanding and trust. 'If we really trust and understand each other, it shouldn't be such a big issue for her [his partner] to sleep with another person for one night.' Elaborating on his ideas about an open relationship, he emphasized that enjoying azadi (freedom) was an important part of his hoviyat (identity), which he thought could be realized in a relationship involving mutual trust and acceptance of each other's sexual desires.

Such articulations of free sexuality also characterized the conversation that I had with Tara, a female journalist in her thirties. Of all interviewees, Tara was the one with the shortest period of residence in the Netherlands. She had left Iran after her mother and brother were arrested during the Iranian Green Movement protests following the reelection of Mahmood Ahamdinejad in the summer of 2009. When she was a child, her father was executed for political reasons. Because of her recent social media activities against the Iranian regime, she was forced to leave the country. About life in the Netherlands, she said, 'I never felt I was in a new environment. [...] I have heard that for some people it is strange to see a couple kissing in public. Not for me.' She then explained that her life was never normal and that she was not easily shocked. In Iran she had been a yaghi (rebel). To illustrate this, she said:

Once, when I was 17 and the whole family was invited to our house, I had an appointment with a hairdresser to depilate my eyebrows. I went there and this woman made my eyebrows very thin. Then she asked me if wanted some highlights in my hair. I said "yes". When my mother saw me coming, she almost had a stroke. Imagine that the whole family and friends and relatives were coming. This was clearly not acceptable. They didn't know how to deal with me, as I was such a yaghi.

In the Netherlands, Tara continued living as a yaghi. Her previous relationship with someone who was 'neither a woman, nor a man' had led to confusion and gossip among family, friends and colleagues, 'even those who consider themselves intellectuals'. Her partner was born as a woman, but felt, dressed and behaved more like a man. 'They don't understand me. I could use the term "queer", but that is probably too difficult for them to understand.' However, Tara appreciated the challenges that she had to face because of their relationship:

I had to fight hard for this relationship. One of the things that I like about this relationship was that after a long time, there was 
something that I had to fight for. It's difficult to explain this feeling. There is something rebellious about it, anarchism. I love anarchism.

She explained that, in her view, the gender of the partner should not matter in a relationship and that she saw it as her task to try to break this taboo:

I believe that everybody should fight against taboos in society. [...] You must have jor'at [the courage] to do that. [...] I think I'm a bit divooneh [crazy]. I don't know the reason, but I know that in my life I have never accepted social norms.

Tara presented herself as someone with the personal tendency, but also a selfproclaimed social duty, to transgress gender, sexuality and other norms.

Neda, a young single woman who came to the Netherlands at the age of four, emphasized that she had difficulties in making a clear distinction between the Dutch and Iranian contexts in terms of feelings of belonging. Except for a phase during which she became very interested in Iranian culture and music, to find out 'who I was', she felt neither particularly Dutch nor Iranian. In fact, as a student, her professor had to convince her to conduct her research in Iran, since she was more interested in Spain and had learned Spanish to prepare herself for her Bachelor research project. 'So just because I was born in Iran and my parents are Iranian, I was supposed to find Iran interesting.' Instead, she preferred living in different countries to maintain her autonomie (Dutch for autonomy). The number of her Iranian friends, however, is slowly growing. 'I have found out that there are interesting people among Iranians as well [she laughs]. No seriously, some of them are very intelligent and open-minded. Others aren't.' Talking about Iranians and sexuality more specifically, she said:

Look, as I said, the Iranian community is very diverse. [...] For example, I have an Iranian female friend who works at Shell. [...] She calls me a whore, as a joke. For her, my way of dealing with sexuality is very strange. I have too many boyfriends, she thinks. I keep telling her that I don't have to be in love to have sex with someone. She doesn't get that. Still, this doesn't affect our friendship, because she is a mature person. Of course, I don't know whether she judges me or not. But, I don't care about that.

Neda feels more understood by 'open-minded' people, a word that she used in English, regardless of their cultural or ethnic background. To truly accept that a woman can have many sexual relationships without being in love, as Neda proposes, goes beyond cultural and ethnic boundaries. 
Sahar, a woman in her early twenties, expressed the same kind of dynamic notion of sexual orientation when reflecting upon her life.

When I was seventeen or eighteen, I kept trying to define myself. Am I homosexual? Bisexual? Now, I don't even try. I wake up every day as a different person. I want to be all these persons.

This multiplicity of gendered and sexual subjectivities that Sahar recognized in herself was something that she also ascribed to others.

I don't see just a woman or a man because of certain bodily characteristics. I often see both femininity and masculinity in the same person. Therefore I can fall in love with men, women or something in between.

What does determine her choices regarding her relationships are 'madness' and 'love':

I think that only madness and love are the right motivations to do things. That makes it beautiful. Being in love should be out of madness. I strongly believe that things like marriage, relationships, men, women, homosexual, bisexual... none of these have an intrinsic meaning.

According to Sahar, the meaning of relationships and sexual attraction are continuously to be discovered in dynamic relationships rather than being predefined through socio-cultural gender and sexuality norms and values. 'Love' and 'madness' are concepts that allow for such contingency, unpredictability and particularity. Romance, conceptualized as 'love' and 'madness' is not rejected, but disconnected from commitment. It is, in fact, celebrated as part of a contingent yet profound feeling between people, while transgressing normative categorizations of sexual orientation and gender.

In the narratives outlined in this section, a longing for and idealization of, transgression in relation to sexuality and the self can be identified. Sexualities and selves claimed in these narratives go beyond what these young research participants perceive as 'normal'. The exclusivity of the self is emphasized through expressions such as: 'no one wants to live like this, except me', 'enjoying freedom is an important part of my identity', 'I think I'm a bit crazy', 'my perceptions completely changed here', 'I have too many boyfriends, she thinks' and 'I wake up every day as a different person'. To enable the constructions of an exclusive self, transgressive sexualities are embraced: open relationships, rejecting the concept of nuclear family, having a partner that is neither a man nor a woman, emotional 
independence, decoupling sex from romance, rejecting fixed gender and sexual identity categories.

\section{Embedded transgressions}

On the one hand, the previous accounts of sexuality and the self seek to provide alternatives to perceived existing norms on sexuality in (Iranian) Dutch sexual culture through embracing open relationships, questioning the nuclear family and rejecting categories of sexual and gender identities. On the other hand, however, they imply other norms: an open-minded, liberal, courageous, autonomous, independent, free self is idealized and claimed. Against this ideal self, an 'other' is implicitly positioned who fails to see through sexual taboos and is unable to understand and appreciate sexual and gender practices that go beyond those taboos.

Furthermore, the previous accounts of sexuality and the self depend on the very discourses that they attempt to transgress by constantly refereeing to them: sex is only meaningful in the context of love, sex is supposed to happen between two people, the nuclear family is the ideal setting for child rearing, living together is the appropriate arrangement for two people in a long-term romantic relationship and people are either men or women and heterosexual or homosexual. It is in relation to, and not outside, these normative frames that the research participants' positions become transgressive.

Both the normativity implied in the acts of sexual and identity transgression and the dependence of these transgressions on other perceived norms attest to their social embeddedness. It is within, rather than in opposition to, a certain sociocultural context that certain acts can be considered transgressive. One of the discussions within the queer studies regards the question of whether queer subjectivities and sexualities actually manage to challenge the norm and the normal (Halperin, 1995; Spargo, 1999; Sullivan, 2003). One way of engaging with this issue is to use ethnographic data in which extensive attention is paid to the sociocultural context in which the queer subjectivities and sexualities take place. The data from my research shows that challenging the norm and the normal happens only partially: certain norms about proper sexualities and relationships are challenged, while other norms about liberated selves and sexualities are produced.

Another discussion that concerns possible normativity of queer subjectivities and sexualities is their potential homogenizing effect, despite the firm rejection of identity politics and the non-assimilation message of queer. The implicit ethic of fluidity, ambiguity and indefinability as promoted by queer, suggests a libertarian ideal and a promise of progression. An exclusionary logic underlies this suggestion, assuming the queer is more enlightened than the non-queer. This exclusionary logic of progression certainly characterizes various accounts of sexuality and the self among the young Iranian Dutch research participants in this paper. 
As part of dealing with the tension between non-normativity and exclusionary potential of transgressive sexualities and selves, what we should take into account in case of the data presented in this paper is the background of the participants: they all come from middle-class, politically engaged families, are highly educated and concerned with social and political issues themselves and live in highly urbanized areas. According to the sociologist Henning Beck 'urban relations' provide people with an 'inner, potential freedom from 'being oneself' connected with anonymity and non-committedness' (1998: 219). In such a context people might feel less constrained in finding self-chosen belongings and enjoy more possibilities to transgress societal norms while running a relatively slim chance of being noticed or judged. I recognize the importance of an urban setting with regard to the range of possibilities that it provides for different subjectivities and sexualities. At the same time, certain opportunities seem to be employed only by particular groups of people. In the research presented here, those subjectivities and sexualities are idealized and claimed that prioritise the individual's autonomy, sexual needs and freedom. Issues of class and ideology then become crucial in understanding the opportunities offered by urban relations. This raises the question of what opportunities become available to whom in urbanized contexts?

\section{Transgressive embeddedness}

In the transgressive accounts of sexuality and the self presented in this paper, as discussed in the previous section, an idealization of a liberal attitude is apparent. This ideal goes hand in hand with a sense of progress, a move from restriction towards freedom to be realised through the constructions of certain sexualities and selves. Joseph Massad, professor of modern Arab politics and intellectual history, connects liberationist notions of sexuality to 'orientalist fantasy and scholarship' from the nineteenth century onward (2008: 9). He states that both Western and non-Western elitist accounts of sexuality have been ascribing civilizationist and cultural values to different sexual practices among colonized people along an evolutionary schema that constitutes a dichotomy between backward/restrictive/misogynist/homophobic and civilized/tolerant/open/liberated sexual cultures. According to Massad, the same orientalist impulses are currently at work, for instance in case of what he calls the assimilationist human-rights-based 'The Gay International' project that takes up the task of protecting and liberating the oppressed gay people around the world (2007: 161).

In line with this post-colonial discussion, Hamid Dabashi (2011), professor of literary studies, provides a critical examination of the work and the role of immigrant 'comprador intellectuals' (cultural broker) in Western countries, focusing primarily on the book Reading Lolita in Teheran by the Iranian-American author Azar Nafisi (2003). This internationally famous memoire and best-seller has been noticed for its anti-Islamic and pro-Western sentiments. The book is about Nafisi's secret gatherings with a group of promising students in her house in 
Tehran after the Islamic revolution, during which they discussed Western literary masterpieces, such as Vladimir Nabokov's Lolita. The prominence of Lolita in the title, even though it is not the only work they discussed, suggests a brave act of transgression: discussing controversial topics of sexuality under the restrictive rules of the Islamic regime. Although pointing to 'legitimate concerns about the plight of Muslim women in the Islamic world', Dabashi claims, a principle effect of Nafisi's work is that it functions as 'a means of manufacturing trans-regional cultural consent to Euro-American domination' (2011: 69, 71). Comprador intellectuals, Dabashi argues, help building up an ideological ground for, and therefore facilitate imperial hegemony.

Also in the context of Europe elitist tendencies to celebrate freedom from restrictive rules of an Islamic cultural background can be found among Iranian diaspora. Joan Scott (2005) and Saba Mahmood (2006, 2009) have noticed a trend in the work of a number of authors with an Iranian background in France, which they qualify as 'orientalist narratives' characterized by an excessive critics of oppression in Islamic cultures and an uncritical celebration of freedom in the West. The result is the production of a polarized vision of the world. Gender and sexuality are often the main topics of such narratives. ${ }^{2}$

In Dutch discourses on integration, citizens with a Moroccan and Turkish origin are regularly identified as groups that experience difficulties in dealing with certain issues of sexuality and or gender due to their Islamic background. Given this politicized context, the question arises: what is the meaning of the accounts of transgressive sexualities and the self discussed in this paper? Although none of the research participants explicitly referred to an evolutionary universal model of sexuality from backward to civilized, normative notions of transgressive liberal sexualities were expressed and applauded. Does this then, regardless of their intention, make them accomplice to orientalist framings of 'us' and 'them'? Do they either consciously or unconsciously contribute to exclusionist politics?

As valuable as the insights from the aforementioned post-colonial critical perspective are, their main focus remains on the Western context. The construction of civilizationist rhetoric in discourses on sexuality and the integration of Islamic migrants in Western societies, tends to position those Muslim others as merely the victims. The possibilities for negotiation and agency of the people involved are overlooked. The research participants in this paper are primarily concerned with overcoming what they experience as limiting in their everyday life by claiming transgressive sexualities and selves. What is the place of such everyday liberationist yet normative engagements in the post-colonial critical discussions on the instrumentalisation of sexuality in exclusionary politics? These engagements are necessarily embedded in such politics, but how do they relate to it? More empirical work on transgressive sexualities and selves at the local level would be needed to gain a better understanding of their connection with and entanglement in transnational politics. 


\section{Notes}

1 This paper is based on a chapter from my dissertation, titled Sexual SelfFashioning among the Iranian Dutch. As partially revealed by the title, my $\mathrm{PhD}$ research was about constructions of sexuality in processes of self-fashioning in the Iranian Dutch community. ${ }^{1}$ I focused on the three topics of premarital sexuality, homosexuality and non-marital cohabitation, and looked for dominant discourses on sexuality and the self using 4 different qualitative methods to collect data: oneon-one conversations with 30 people, 5 focus group discussions with another 22 participants, participant observation ( 8 occasions selected for analysis) and online text analysis (65 selected for analysis). This paper centers on a small group of the respondents who presented themselves as transgressive with regard to their stances on issues of sexuality. They explicitly positioned themselves outside the mainstream Iranian Dutch (sexual) culture. As such, they claimed to be a minority within a minority.

${ }^{2}$ For instance Dow with Veils (2003) and How Can One Be French? (2009) by Chahdortt Djavann, Tears of the Exile (2004) by Ladane Azernour, My Life as a Traitor (2008) by Zahra Ghahramani and Prisoner of Tehran: A Memoire (2008) by Marina Nemat. Comparable examples in the Netherlands are: Afshin Ellian, professor of law, who takes it as his 'duty to defend freedom and criticize Islam' (Nov. 2, 2012, Volkskrant), Sooreh Hera (pseudonym), an artist who won publicity with her photo project Adam and Ewald, in which scantily-clothed homosexual Middle-Eastern looking men are presented wearing masks of prophet Mohammad and the first Shi'i imam Ali in erotic setting such as a bedroom (Soorehhera.com, accessed January 15, 2014), ${ }^{2}$ and Ehsan Jami, a writer and former politician, who co-founded the Dutch Central Committee for Ex-Muslims with the aim 'to break the taboo of apostasy in Islam' and to 'defend freedom' (May 2, 2007, NOVA).

\section{Bibliography}

Beck, Henning. (1998). Citysex: Representing Lust in Public. Theory, Culture \& Society, 15(3), 215-241.

Central Bureau of Statistics, (2003). Jeugd 2003; cijfers en feiten. Den Haag \& Heerlen: CBS.

Dabashi, Hamid. (2011). Brown Skin, White Masks. London: Pluto Press. 
Halperin, David. (1995). Saint Foucault: Towards a Gay Hagiography. Oxford: Oxford University Press.

Hessels, Thomas. (2002). Iraniërs in Nederland: een profiel. Ministerie van Buitenlandse Zaken en koninkrijkrelaties.

Mahmood, Saba. (2006). Retooling Democracy and Feminism in the Service of the New Empire. Quie Parle, 16(1), 117-143.

Mahmood, Saba. (2009). Feminism, Democracy, and Empire: Islam and the War on Terror. In: H. Herzog \& A. Braude (eds.), Gendering Religion and Politics. Untangling Modernities. Jerusalam and Harvard: Palgrave Macmillen.

Massad, Joseph A. (2007). Desiring Arabs. Chicago \& London: The University of Chicago Press.

Massad, Joseph A. (2013). The Empire of Sexuality: An Interview with Joseph Massad. Last modified May 5, 2013, accessed January 15, 2014: http://www.jadaliyya.com/pages/index/10461/the-empire-of-sexuality_aninterview-with-joseph-m

Spargo, Tamsin. (1999). Postmodern Encounters. Foucault and Queer Theory. Cambridge: Icon Books.

Sullivan, Nikki. (2003). A Critical Introduction to Queer Theory. New York: New York University Press.

Rahil Roodsaz is a researcher at Atria, Institute for Gender Equality and Women's History in Amsterdam and a postdoctoral researcher on sexual education programs for young people in Bangladesh at the Institute for Gender Studies of the Radboud University Nijmegen in the Netherlands. 